\title{
Instruments for On-line Monitoring of Transformers
}

\begin{abstract}
The main objective of the paper is to describe the experience with newly developed monitoring system for transformers with oil-paper insulation system. From the view of operation reliability, it is necessary for operators to provide a monitoring of transformer's failure free operation. The application of monitoring system enables to warn timely of the rising failure and also decrease of degradation of single subsystems of machine. When failure is detected, it is important to support this detection by other measurements that would lead to exact determination of the failure. SFRA analysis (Sweep Frequency Response Analysis) is such additional method in our monitoring.
\end{abstract}

V. Mentlík ${ }^{1}$, P. Prosr $^{1}$, R. Polanský ${ }^{1}$, J. Michalík ${ }^{2}$, M. Brandt ${ }^{2}$

${ }^{1}$ University of West Bohemia,

Faculty of Electrical Engineering, Department of Technologies and Measurement, Univerzitní 26, 30614 Pilsen (Czech Republic)

Phone/Fax number: +420 377634 519/ +420 377634 502, e-mail : prosr@ket.zcu.cz

${ }^{2}$ Research Centre of Mechatronics Systems

EVPÚ a.s. Nová Dubnica and Faculty of Electrical Engineering ŽU in Žilina

Univerzitná 1, 01026 Žilina (Slovakia)

Phone/Fax number: +421 41513 5063/+421 41513 1529, e-mail: michalik@fel.uniza.sk, brandt@fel.uniza.sk

\section{Key words}

electrotechnological diagnostics, dissolved gases, experimental laboratory, winding temperature, operation characteristics, SFRA analysis

\section{Introduction}

The electrotechnological diagnostics is the important instrument that provides safe and reliable operation of electric devices. This condition depends on quality of input elements used for manufacturing of single parts of device and also on evaluation of complex device properties.

The diagnostic process can be realized by two different accesses. The first one, so called off-line diagnostics, monitors diagnostic characteristics on shut down machine. Operators prefer the second access (on-line diagnostics), which enables evaluation of machine condition along its common operation time.

The realization of such on-line diagnostic system demands a compromise between expected costs of design and operation of diagnostic system, between estimation of savings due to decreasing number of breakdowns, new strategy of servicing and extension of lifetime of monitored machine. Hence only those specific characteristics, which have close connection to damages and degradation processes in machine, are recommended to observe. [1]

\section{Experimental laboratory of diagnostics}

The main aim of the paper is to describe and present our first experience with developed monitoring system for on-line diagnostics of transformers. Since the experimental usage of such system for purpose of checkout is very risky in these cases, a laboratory for test operation was developed. The laboratory keeps at disposal two distribution transformers (supply T2 transformer and experimental T1 transformer - see Fig. 1) with following characteristics:

T1: BEZ kTO 253/22, no. Bra 42931, MY 1958, 30 kVA, Yz1, 23100/22000/20900 V/ 400/230 V, uk= 4,96\%, $0,787 \mathrm{~A} / 43,3 \mathrm{~A}$

and T2: BEZ aT 0294/22, no. 231279, MY 1983, 100 $\mathrm{kVA}, \mathrm{Yzn} 1,22000 \pm 2 * 2,5 \% \mathrm{~V} / 400 / 230 \mathrm{~V}, \mathrm{uk}=3,96 \%$, $2,62 \mathrm{~A} / 144,4 \mathrm{~A}$.

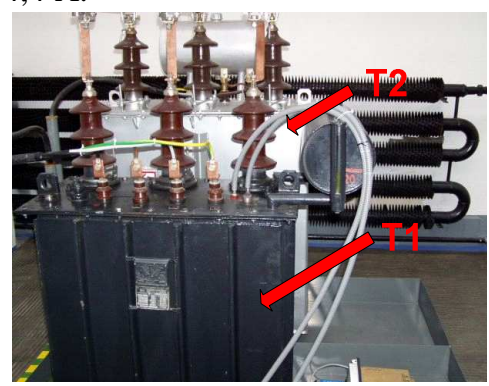

Fig. 1. Transformers in laboratory

The main advantage of such laboratory is the possibility of measurement of selected characteristics response to limiting states of transformer. Measured results then allow to determine the limiting values for selected model 
situations and also specify the connection of on-line monitoring data and common off-line diagnostic methods.

\section{Selection of monitored characteristics}

The condition of oil-paper insulation system is the main diagnostic indicator that influences failure-free operation of transformers. Monitoring of such characteristics, which concern in the failure of machine is necessary when safe and reliable operation is required.

Selection of suitable diagnostic methods is the first important objective during the design of monitoring system. As the aging of transformer insulation system is affected mainly by changes of temperature and electrical operation characteristics [2], [3], [4], the observation of these characteristics is included in our monitoring system. The list of these characteristics is presented bellow.

\section{A. Temperature characteristics}

A winding temperature as a temperature characteristic is recorded by two sensors NEOPTIX T2 installed on the top and in the middle of primary winding of a middle phase. Fibres are brought out the transformer through the special bushings in the top of the transformer vessel (see Fig. 2) to the control unit (NEOPTIX T/Guard System).

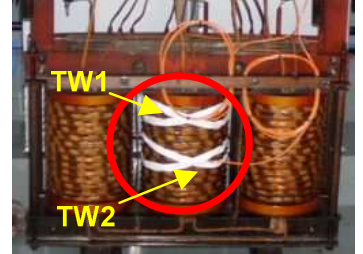

a)

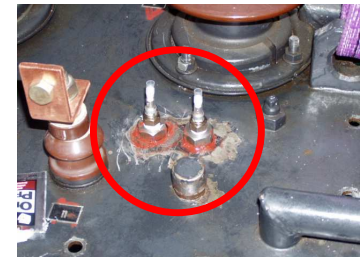

b)
Fig. 2. a) View of fiber optic sensors of winding temperature in experimental transformer b) bushings, through which they are brought out the transformer vessel

This unit evaluates the measured data of winding temperature and communicates on-line with central computer (including Neolink software) through the RS232 interface.

\section{B. Dissolved gases and moisture level}

Dissolved gases in the oil and moisture level are observed by Hydran M2 sensor, which is set on drain valve of transformer vessel. Hydran M2 sensor is sensitive to the most common gases in the oil such as hydrogen, carbon monoxide, acetylene and ethylene. However the sensor records so called composite value with different sensitivity to single gases, which is quite disadvantage (see Table I) [5]

TABLE I. - Sensitivity of Hydran M2 sensor to different gases

\begin{tabular}{|c|c|}
\hline hydrogen $\mathrm{H}_{2}$ & $100 \%$ \\
\hline carbon monoxide $\mathrm{CO}$ & $18 \%$ \\
\hline acetylene $\mathrm{C}_{2} \mathrm{H}_{2}$ & $8 \%$ \\
\hline ethylene $\mathrm{C}_{2} \mathrm{H}_{4}$ & $1,50 \%$ \\
\hline
\end{tabular}

Processing of obtained data may be proceeded via Hydran Host software or it is possible to process them in spreadsheet editor eventually.

\section{Operation characteristics}

Currents of single phases are measured in the secondary part of T1 transformer, where measuring transformers with the current ratio of 100/5 A are installed. Other operation characteristics (besides the currents) such as voltage or active, reactive and apparent powers are measured by Lovato DMK 20 industrial multimeter [9]. Obtained data are transferred to computer via RS232 interface, where the software performing the automatic data displaying and saving is installed.

\section{Experimental operation of monitoring system}

The first experimental monitoring of $\mathrm{T} 1$ transformer was performed on 28. 1. 2008. Supply of T1 transformer was provided by $\mathrm{T} 2$ transformer (T2 $400 / 22000$ and $\mathrm{T} 1$ $22000 / 400 \mathrm{~V})$. The loading mode was changed during the experimental operation of transformer.

28.1.2008 - firstly the transformer was loaded on $10 \%$ of rated power by resistive load of $60 \Omega$ in the phase (i.e. the load of 3,8 $\mathrm{A}$ in the phase).

7.2. 2008 - loading was increased on $35 \%(15,2 \mathrm{~A}$ in the phase). Loading had to be reduced on $10 \%$ of rated power again, as winding temperature and value of gases increased rapidly. Such decrease of load resulted in steady values of winding temperature, moisture and level of gases in the oil.

13.2. 2008 - unbalanced resistive load $\left(I_{1}=0\right.$ A, $\mathrm{I}_{2}=7,8 \mathrm{~A}, \mathrm{I}_{3}=3,8 \mathrm{~A}$ ) was experimentally created.

15.2. 2008 - both transformers were taken out of service for the purpose of oil sampling for gas chromatography analysis.

18.2. 0008 - the change of the resistive load to a balanced R-L load of 2,4 kVA power (12,5\% of rated power of T1 transformer) was done.

5.3. 2008 - the R-L load has been combined with asynchronous motor (power of $15 \mathrm{~kW}$, working in open circuit). This load presents approx. $30 \%$ of rated power of $\mathrm{T} 1$ transformer.

11.3. - 23.4. 2008 - transformer operated with alternating connection and disconnection of loading (asynchronous motor) Then transformer was switched off and load transfer to another laboratory followed.

12.5. 2008 - transformer was switched off because of SFRA analysis and insulation resistance measurements and started up again on load of $15,1 \mathrm{kVA}-$ i. e. $50 \%$ of rated power.

5.6. 2008 - the experimental transformer was taken out of service by reason of increase of gases and moisture in the oil and increasing winding temperature as well. Measurement of insulation system condition proceeded at $60{ }^{\circ} \mathrm{C}$. Polarization index of only 1,16 was recorded, insulation resistance ranged from 350 to $650 \mathrm{M} \Omega$ after conversion to the temperature of $20{ }^{\circ} \mathrm{C}$.

13.6. 2008 - insulation resistances were measured again. The polarization index of 1,47 was obtained and 
resistances ranged from 2,98 $\mathrm{G} \Omega$ to $4,13 \mathrm{G} \Omega$. Considering this fact, the transformer has been switched on again, but only with resistive load set on $10 \%$ of rated power.

14.7. 2008 - both transformers were switched off due to power failure.

15. 7. 2008 - transformers have been in operation again on the load of $10 \%$.

22.10. 2008 - the load of $65 \% \mathrm{~S}_{\mathrm{N}}$ power was connected (resistors and asynchronous motor).

\section{Obtained data of selected characteristics}

Winding temperature was gradually increasing along the operation from 29.1. to 6.3. (Fig. 3). However temperature variation was recorded during the whole transformer operation from its first startup till 29.10. 2008. As we compare obtained temperature results, (see the example of data file in Table II.) with the way of transformer load presented in previous Chapter, the increase of temperature owing to transformer load is evident.

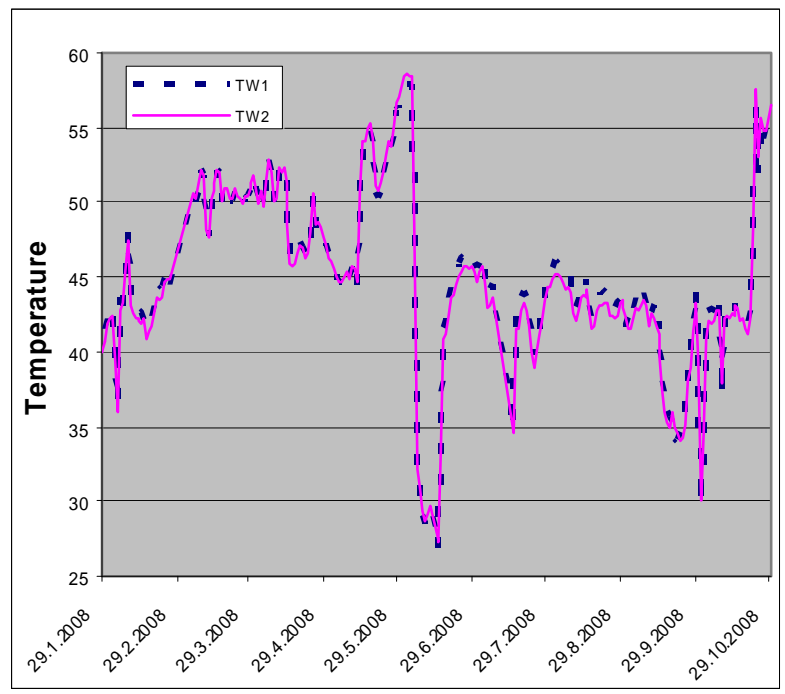

Fig. 3. Winding temperature in measurement interval from 29.1.to 29.10. 2008

TABLE II. - File structure of obtained temperature data

\begin{tabular}{|c|c|c|c|}
\hline $\begin{array}{c}\text { Neoptix, Inc. } \\
\begin{array}{c}\text { Instrument } \\
\text { (serial): }\end{array}\end{array}$ & $\begin{array}{c}1 \\
\text { (TGD186A) }\end{array}$ & $\begin{array}{c}1 \\
\text { (TGD186A) }\end{array}$ \\
\hline Channel name: & & $1:$ & $2:$ \\
\hline Channel \# : & & 1,00 & 2,00 \\
\hline dd/mm/yyyy & hh:mm:ss & & \\
\hline 29.1 .2008 & $11: 42: 48$ & 40,30 & 39,50 \\
\hline 29.1 .2008 & $11: 57: 48$ & 40,40 & 39,50 \\
\hline 29.1 .2008 & $12: 12: 48$ & 40,40 & 39,50 \\
\hline 29.1 .2008 & $12: 27: 48$ & 40,40 & 39,60 \\
\hline 29.1 .2008 & $12: 42: 48$ & 40,40 & 39,60 \\
\hline 29.1 .2008 & $12: 57: 48$ & 40,50 & 39,60 \\
\hline
\end{tabular}

When we focus on results of gases and moisture level measurement, certain connection between winding temperature and moisture level in the transformer oil is obvious. At the moment of transformer's start up, the level of dissolved gases was 29 ppm (composite value), moisture level of around 14,2 \% and water level of 12 ppm was recorded (measured by Hydran M2 sensor). When we compare these results with gas chromatography data obtained via Kelman Transport $\mathrm{X}$ before the monitoring, (initial values were: $\mathrm{H}_{2}=26 \mathrm{ppm}, \mathrm{H}_{2} \mathrm{O}=25$ ppm, $\mathrm{RH}=15 \%$ ), no expressive difference was observed.

The figure 4 illustrates the trend of gases and moisture level along the operation of experimental transformer.

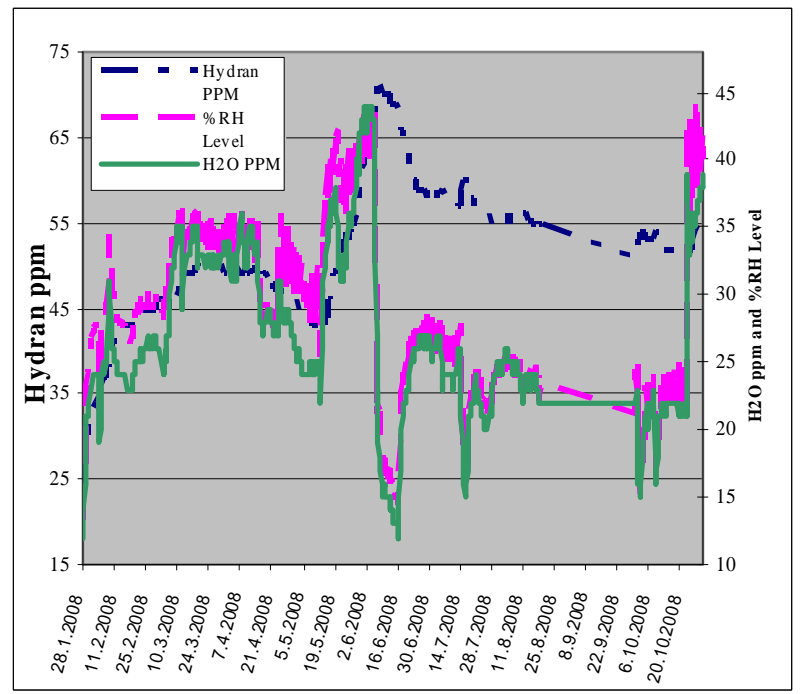

Fig. 4. Trend of gases and moisture level in oil in measurement interval from 29.1. to 29.10. 2008

Increase of gases and moisture level is recorded (accordingly to winding temperature) always owing to increasing transformer load. Sharp decrease on the other hand is observed mainly at the moment of total shut down of transformer (e. g. on 15.2., 7.6., 14.7. etc.) or owing to decreasing transformer load (4.4). For more obvious presentation see following pictures (Fig. 5 and Fig. 6), where obtained values of winding temperatures, gases level and moisture in the oil in shorter time interval (5.-29.6. 2008) are presented.

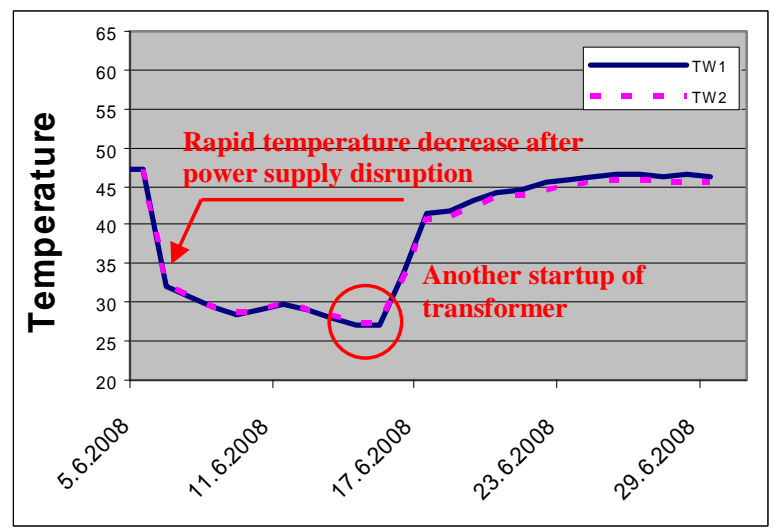

Fig. 5. Detailed scheme of winding temperatures in the range from 5. to 29.6. 2008 


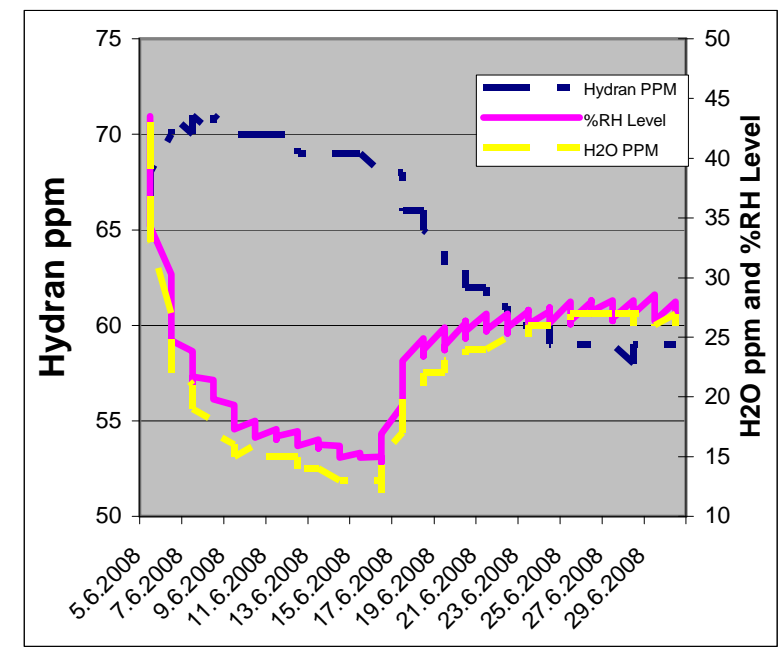

Fig. 6. Detailed scheme of gases and moisture level in the oil in the range from 5. to 29.6. 2008

Gradual decrease of winding temperature was observed after shut down of the transformer on 5.6. Also moisture level in the oil copies this trend very well. The moisture returns to the solid component of transformer insulation during the cooling process. The gradual decrease occurs also in the case of dissolved gases in the oil.

Operation characteristics are also included in monitoring system. Currents of single phases are measured in the secondary part of experimental transformer, values of voltage, active, reactive and apparent powers are measured by Lovato DMK 20 industrial multimeter. Values of operation characteristics are saved for further monitoring of way of transformer load along its operation. Following table presents the example of saved operation characteristics.

TABLE III. - Saved operation characteristics

\begin{tabular}{|c|c|c|c|c|c|c|c|c|c|c|}
\hline Datum & Cas & $\begin{array}{l}01-V \\
\mathrm{~L} 1[\mathrm{~V}]\end{array}$ & $\begin{array}{l}01-\mathrm{V} \\
\text { L2 [V] }\end{array}$ & $\begin{array}{l}01-V \\
\mathrm{~L} 3[\mathrm{~V}\end{array}$ & $\begin{array}{l}01-\mathrm{A} \\
\mathrm{L} 1[\mathrm{~A}]\end{array}$ & $\begin{array}{l}01-A \\
L 2[A]\end{array}$ & $\begin{array}{l}01-\mathrm{A} \\
\mathrm{L}[\mathrm{A}]\end{array}$ & $\begin{array}{l}01-W \\
\text { T INT } \\
{[\mathrm{KW}]}\end{array}$ & $\begin{array}{l}01-V A \\
\text { T INT } \\
{[k \backslash / A]}\end{array}$ & $\begin{array}{c}01 \text { - Var } \\
E Q V \\
{[\mathrm{k} / \mathrm{ar} r}\end{array}$ \\
\hline 26.2 .2008 & $0: 04: 03$ & 225 & 227 & 226 & 5,73 & 5,84 & 5,98 & 3,96 & 4,00 & 0,48 \\
\hline 26.2 .2008 & D: $19: 03$ & 225 & 227 & 226 & 5,74 & 5,84 & 5,98 & 3,96 & 3,99 & 0,54 \\
\hline 2.2008 & $0: 34: 03$ & 225 & 227 & 227 & 5,76 & 5.86 & 6.01 & 3,95 & 3,99 & 0,49 \\
\hline 26.2 .2008 & $0.49: 03$ & 225 & 227 & 227 & 5,74 & 5.85 & 5.99 & 3,96 & 4,00 & 0.52 \\
\hline 26.2 .2008 & $1: 04: 04$ & 225 & 227 & 226 & 5,73 & 5,84 & 5,99 & 3,95 & 3,99 & 0,53 \\
\hline & & 225 & 227 & 227 & 5,75 & 5,85 & 6,00 & 3,95 & 3,98 & 0,52 \\
\hline 2008 & $1: 34: 04$ & 225 & 227 & 227 & 5.75 & 5.85 & 6,00 & 3,95 & 3.99 & 0,50 \\
\hline 2008 & $1: 49: 04$ & 225 & 227 & 227 & 5,75 & 5.86 & 6,01 & 3,96 & 3.99 & 0.51 \\
\hline 26.2 .2008 & $2: 04: 04$ & 225 & 227 & 227 & 5,75 & 5,86 & 6,01 & 3,97 & 4,01 & 0,55 \\
\hline 2.2008 & $2: 19: 04$ & 226 & 228 & 228 & 5,76 & 5,87 & 6,03 & 3,97 & 4,01 & 0,53 \\
\hline 2.2008 & $2: 34: 04$ & 225 & 227 & 227 & 5,76 & 5.87 & 6.01 & 3,98 & 4,01 & 0,53 \\
\hline & $2: 49: 0$ & 226 & 228 & 228 & 5,76 & 5,87 & 6,02 & 3,97 & 4,00 & \\
\hline & $3: 04: 04$ & 226 & 228 & 228 & 5,77 & 5.88 & 6,02 & 3,98 & 4,01 & 0,55 \\
\hline 2.2008 & 3:19:04 & 226 & 228 & 228 & 5,77 & 5,88 & 6,03 & 3,99 & 4,03 & 0,54 \\
\hline 2.2008 & $3: 34: 04$ & 226 & 228 & 227 & 5,76 & 5,87 & 6,02 & 3,99 & 4,02 & \\
\hline 2008 & & 226 & 228 & 228 & 5,76 & 5,87 & 6,02 & 3,97 & 4,01 & 0,52 \\
\hline 2008 & 4:04:04 & 225 & 227 & 227 & 5.75 & 5,86 & 6,01 & 3,98 & 4,01 & 0,55 \\
\hline 26.2 .2008 & & 225 & 227 & 227 & 5,74 & 5,85 & 6,00 & 3,96 & 3,99 & 0,50 \\
\hline 26.2 .2008 & $4: 34: 04$ & 225 & 226 & 226 & 5,73 & 5,84 & 5,99 & 3,95 & 3,99 & 0,52 \\
\hline
\end{tabular}

\section{Comparison of obtained data with SFRA results}

As obvious, trend of gases dissolved in the oil is affected by the load, by winding temperatures or by ambient temperature (temperature conditions refer to possible degradation of insulation system). Due to increasing trend of monitored gases during the machine operation, control measurements for winding condition and transformer core assessment (by SFRA analysis) as well as insulation resistance measurement was performed. Frequency characteristics were measured before the experimental transformer start up to assess the condition of winding and transformer core. Measurement proceeded according to Tab. IV by DOBLE M5100.

TABLE IV. - Measurement of T2 transformer (22/0,4 $\mathrm{kV}$ ) via DOBLE M5100 system

\begin{tabular}{|c|c|c|c|c|c|c|c|c|}
\hline \multicolumn{4}{|c|}{ Open Circuit Tests } & \multicolumn{3}{c|}{ Short Circuit Tests } \\
\hline \multicolumn{3}{|c|}{ HV Windings } & \multicolumn{3}{c|}{ LV Windings } & \multicolumn{3}{c|}{ a-b-c shorted } \\
\hline Test1 & Test2 & Test3 & Test4 & Test5 & Test6 & Test7 & Test8 & Test9 \\
\hline A-C & B-A & C-B & a-n & b-n & c-n & A-C & B-A & C-B \\
\hline
\end{tabular}

Such obtained results [8] become reference values for further measurements and they are required for comparison with the results obtained after transformer disassembly, at scheduled measurement during operation or at failure of machine. The experimental transformer had been disassembled before the first start up because of installation of optical probes for winding temperature measuring. The winding construction and transformer core had been under mechanical stress. Hence control measurement of winding and core condition was performed by SFRA analysis after optical probes were installed and transformer was assembled again (Fig. 7).

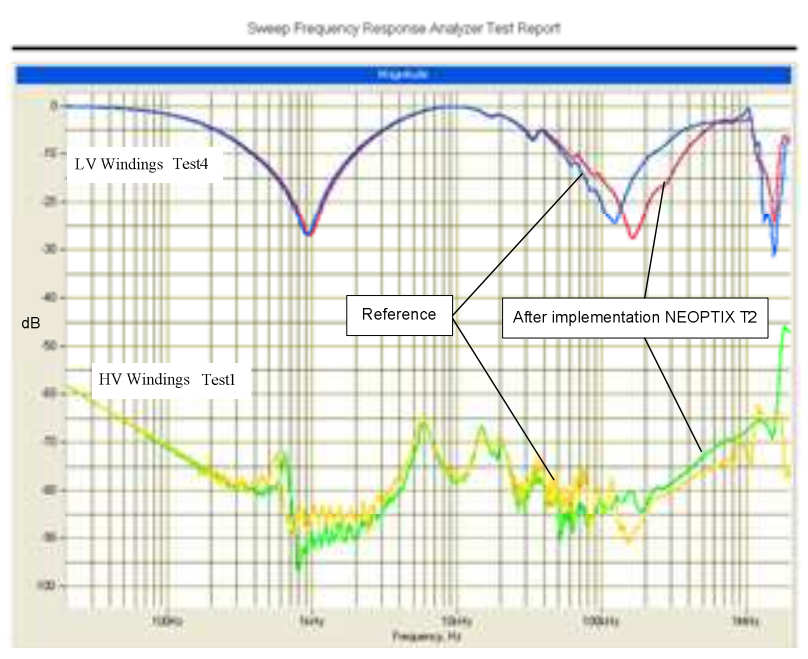

Fig. 7. Analysis of SFRA results after installation of NEOPTIX T2 optical probes before transformer start up

As Fig. 7 shows, mechanical shift towards the transformer core was observed during the disassembly of transformer. However this shift doesn't effect the transformer operation directly, which is also proved by additional measurements of insulation resistances (performed according to STN 351080 via Megger MIT 520). These measurements were done to avoid the insulation damage or presence of turn-to-turn fault.

Data obtained before the transformer start up: $\mathrm{R}_{\text {insulation }}$ :

$\mathrm{LV}-$ ground $=3,88 \mathrm{G} \Omega$

$\mathrm{HV}-\mathrm{LV}=6,94 \mathrm{G} \Omega, \mathrm{Pi}=1,62, \mathrm{C}<0,01 \mu \mathrm{F}$

$\mathrm{HV}-$ ground $=6,64 \mathrm{G} \Omega$

Transformer started up according to schedule described in Chapter 4 after these measurements. Actual SFRA results are presented in following figure (Fig. 8). 


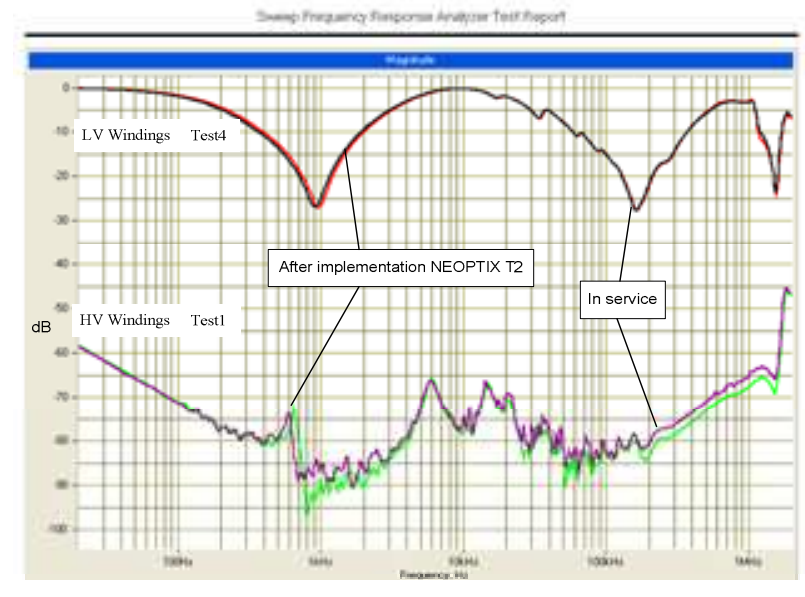

Fig. 8. SFRA results after some time of operation versus results obtained before transformer start up

Specific changes were observed in transformer, as evident in Fig. 8. Frequent changes of load and sudden outages (random switch on and offs, failure states in distribution network leading to lay-ups of transformer) caused small changes in mechanical configuration of winding. These changes can point to mechanical shift of winding towards the transformer core, larger than it was recorded before the transformer's start up. However these changes may be also connected with the changing properties of transformer insulating oil. Insulating oil influences the capacity coupling of winding impedance, (i. e. influences also self and mutual inductance of single windings) [9]. Insulation resistances and polarization index (at $21,3{ }^{\circ} \mathrm{C}$ ) were measured again to avoid the damage of insulation, presence of turn-to-turn fault eventually.

Capacity along the whole measurement was recorded less than $0,01 \mu \mathrm{F}$.

$\mathrm{R}_{\mathrm{iz}}$ :

$\mathrm{HV}-\mathrm{LV}=4,32 \mathrm{G} \Omega, \mathrm{Pi}=1,4$

$\mathrm{HV}-$ ground $=4,96 \mathrm{G} \Omega, \mathrm{Pi}=1,54$

$\mathrm{LV}-$ ground $=4,6 \mathrm{G} \Omega, \mathrm{Pi}=1,41$.

Following these measurements, it is possible to consider the transformer as convenient to demands on operation; nevertheless insulating properties of the whole insulation system have deteriorated during its operation.

\section{Conclusion}

The preventive and continuous data collection and their complex evaluation is the main objective of presented monitoring system. The aim of our measurement was to detect the level of the gradual degradation of machine as a whole. Monitored characteristics for experimental transformer were selected considering these requests. Monitoring system includes those characteristics, which can be used for calculation of approximate residual lifetime of machine with regard to thermal treatment, as well as key characteristics for timely detection of machine failure (gases and moisture in the oil). Experimental laboratory in addition enables to monitor the selected characteristics at different loads of transformer regardless of limits that would occur in common operation.
SFRA analysis is considered to be a good additional method of on-line monitoring, whereas it enables to specify more exactly the information on processes, which can cause eventual failure of machine. However, it is important to obtain enough information in failure-free operation - so called reference curves of frequency analysis. On the other hand, trend when load change appears is more important to monitor than absolute measured values in case of data obtained by monitoring system.

Results point at the changes in transformer from the first start up of machine. It became evident in increasing gases and moisture level in the oil with the slightest load increase and also in control measurement via SFRA analysis. Changes in mechanical configuration of winding (which can point to larger mechanical shift of winding towards the transformer core) or change of insulating oil properties could be the possible effects of changes measured by developed monitoring system.

\section{Acknowledgement}

This article was carried out by the help of Ministry of Education, Youth and Sports of Czech Republic, MSM 4977751310 - Diagnostics of Interactive Processes in Electrical Engineering.

\section{References}

[1] Mentlík, V.; Prosr, P. Aspekty měření teplot ve výkonových transformátorech. In Elektrotechnika v praxi. 2007, roč.17, č.11-12, s.20-24, ISSN 0862-9730.

[2] B. Pahlavanpour "Reducing the risk of insulation failure" Naphtenics market magazine 4/2007.

[3] T. K. Saha, "Review of modern diagnostic techniques for assessing insulation condition in aged transformers", IEEE Transactions on Dielectrics and Electrical Insulation. Vol. 10, pp. 903-917, 2003.

[4] Bräunlich, R. et al. Assessment of Insulation Condition of Large Power Transformers by On-Site Electrical Diagnostic Methods. In International Symposium on Electrical Insulation [online]. Anaheim, April 2000, Paper 13-2.

[5] Hydran M2 Monitoring System, GE Enerhgy, [online], [cit. 13.6.2008] Dostupný z WWW $<$ http://www.gepower.com/prod_serv/products/substation _md/en/hydran_exchange.htm>

[6] Mentlík, V.; Michalík, J.; Polanský, R.; Prosr, P.; Brandt, M. Property Changes of Transformer Oil during Limiting States of Transformer. In CEIDP. Piscataway : IEEE, 2008. s. 309-312. ISBN 978-1-14244-2549-5.

[7] Mentlík, V.; Michalík, J.; Polanský, R.; Prosr, P.; Brandt, M. Property Changes of Transformer Oil during Limiting States of Transformer. In CEIDP. Piscataway : IEEE, 2008. s. 309-312. ISBN 978-1-14244-2549-5.

[8] Gutten, M., Brandt, M.: Analýza stavu olejových transformátorov 22/0,4 kV metódou SFRA. In. Proceedings ELEKTRO 2008, p. 82-85. ISBN 978-808070-845-0.

[9] Singh, J., Sood, Y., R., Verma, P., Jarial, R., K.: Novel method for detection of transformer winding faults sing Sweep Frequency Response Analysis, 1-4244-12986/07, 2007 IEEE 